\author{
Dainius PALIULIS ${ }^{1}$
}

\title{
REMOVAL OF LEAD(II) AND ZINC(II) FROM AQUEOUS SOLUTIONS APPLYING FIBBER HEMP (Cannabis sativa L.)
}

\begin{abstract}
Lead and zinc are heavy metals with toxic properties. These chemical elements are found in wastewater. The article deals with the removal of lead(II) and zinc(II) ions from polluted water using adsorption. As object of researches was selected natural polymer - fibber hemp (Cannabis sativa L.). Big quantities of fibber hemp are produced as waste in textile, agricultural industry, and therefore their usage could help to solve two problems reducing quantity of fibber hemp as waste and reducing of water pollution by heavy metals. $\mathrm{Pb}$ (II) and $\mathrm{Zn}$ (II) ions adsorption with fibber hemp was investigated for contact time, $\mathrm{pH}$, and heavy metal ions concentration impact. $\mathrm{Pb}$ (II) and $\mathrm{Zn}$ (II) ions biosorption rate was highest within the first hour, with optimal their biosorption recorded at $\mathrm{pH}=5.0$. Highest lead and zinc ions removal efficiency was recorded after 240-480 min and reached 60.5 and $61.7 \%$ respectively. This study demonstrated the applicability and effectiveness of fibber hemp in lead and zinc ions removal, which could be applied for the sewage treatment plant in small scale.
\end{abstract}

Keywords: fibber hemp, adsorption, zinc, lead, heavy metals

\section{Introduction}

Heavy metals are one of the most harmful types of pollution. They are one of the dangerous pollutants in soil, marine and even purified industrial wastewater. Heavy metals are non-biodegradable and can easily penetrate into various ecosystems due to their water solubility [1]. Wastewater of modern industries, chemistry, electroplating (including battery production), fertilisers, mining, paper, pesticides, metallurgy, fossil fuels, leather processing and rapid increasing of production, especially in developing countries strongly affect the release of heavy metals [2]. Heavy metals in Lithuania enter industrial wastewater in electroplating, textile, plastics processing, organic paint production and non-ferrous metals industries. In industrial wastewater the highest amounts of heavy metals includes lead, zinc and etc. The cost of maintaining existing industrial wastewater treatment plants is high, and so far there has been a strong focus on the implementing of innovative technologies that are low in cost, low maintenance and energy in comparison with existing technologies [3]. Although chemical precipitation, coagulation, ion exchange, filtration, membrane and other methods have been applied in this purpose, most techniques have some limitations such as requirement of several pre-treatments, some of them are less effective or require high capital costs. Therefore many scientists have applied natural wastes to remove heavy metals from aqueous solutions [4-6]. At present, adsorption is one of the economically advantageous methods of wastewater treatment. Adsorption is reversible and

\footnotetext{
${ }^{1}$ Environmental Protection and Water Engineering Department, Faculty of Environmental Engineering, Vilnius Gediminas Technical University, Vilnius, Sauletekio ave. 11, Lithuania, phone +370 52744725 , email: dainius.paliulis@vgtu.lt
} 
adsorbents can be regenerated by suitable desorption techniques [7]. Adsorption has wide $\mathrm{pH}$ range, high metal binding capacities, and easy operating conditions addition to its low-cost. However, the adsorption efficiency depends on the adsorbent materials [8]. For the adsorption of heavy metals from contaminated water, cheap natural adsorbents such as zeolites, opoca, peat and others can be applied. Natural organic adsorbents are commonly used to remove heavy metals and organic pollutants from surface water. They have good adsorption properties and abundant natural resources, but some of them used once must be disposed [9]. Currently, adsorbents from industrial and agricultural wastes have been the focus of attention: crab shells, activated sludge, rice straw, peanut shells, papaya trunk, rice husks, nymphs, goose-foot leaves, egg shells, swamp mosses, cumin, flax [10]. Agricultural by-products may be heavy metal adsorbents that may be specifically oriented for some metal ions [11]. A lot of lead and zinc ions removal techniques are used in the world, the most common one being the adsorption process, but there is a lack of research of the uses of adsorbents that are easy to obtain and cheap, such as fibber of hemp. As object of researches was selected natural polymer - fibber hemp (Cannabis sativa L.). Big quantities of fibber hemp are produced as waste in textile, agricultural industry, and therefore their usage could help to solve two problems - reducing quantity of fibber hemp as waste and reducing of water pollution by heavy metals. Cannabis belongs to the genus Cannabis in the family Cannabaceae and may include three species, Cannabis sativa, Cannabis indica, and Cannabis ruderalis. According to the data of European Industrial Hemp Association (EIHA), around 42500 hectares of hemp was grown in the European Union in 2017, and compared to 2016, the area increased by about $30 \%$ (compared to 33300 ha in 2016). According to the data of the Agricultural Information and Rural Business Center, the area declared for fibber hemp in Lithuania in 2014 was 1062.89 ha, in 2015 - 2348.12 ha, in 2016 - 2453.84 ha, in 2017 - 2479.39 ha. In 2018, JSC Naturalus pluostas was established in Lithuania, which hemp stems processed into fibbers suitable for the textile, paper, construction industry, and the remaining materials - spikes and fine particles - were used in agriculture and industry, as well as in fuel production. Hemp fibber raw material is supplied to Lithuanian and foreign markets [12].

Cellulose in fibber hemp (Cannabis sativa L.) can be chemically activated and adapted for heavy metal ion adsorption, but the use of this adsorbent for the removal of heavy metal ions from aqueous solutions has not been studied widely. In this study was investigated the application of the fibber hemp for heavy metals adsorption. The purpose of this article is to investigate the dependence efficiency of the removal of lead(II) and zinc(II) ions from polluted water on contact time, heavy metal concentration and solution $\mathrm{pH}$ using fibber hemp as adsorbent.

\section{Materials and methods}

Preparation of adsorbent. The low-cost fibber hemp was used as an adsorbent. Fibber hemp was washed 3 times with deionised water (Demiwa 3 roi system). The washed biosorbent was dried at room temperature $\left(21^{\circ} \mathrm{C}\right)$ for 72 hours. The dried mass of adsorbent was crushed in a porcelain mortar to a homogeneous mass and spread through a $0.2 \mathrm{~mm}$ sieve with vibratory sieve shaker Retsch AS 200 [13]. Fraction with fibber hemp diameter $<200 \mu \mathrm{m}$ was selected for experimental research. The prepared adsorbents were stored in plastic containers at constant temperature $\left(21{ }^{\circ} \mathrm{C}\right)$ to minimise the influence of moisture [13]. Surface images of fibber hemp were obtained by microscopy. 
Effect of heavy metal concentrations on removal of heavy metals. AAS standard solutions of lead and zinc (ROTI ${ }^{\circledR}$ STAR) were used as the source of $\mathrm{Zn}$ (II) and $\mathrm{Pb}$ (II) ions in the polluted water. The aqueous solutions containing cations of $\mathrm{Zn}^{2+}(3.0 ; 6.0 ; 15.0 ; 30.0$; $60.0 \mathrm{mg} / \mathrm{L})$ and $\mathrm{Pb}^{2+}(0.5 ; 1.0 ; 2.5 ; 5.0 ; 10.0 \mathrm{mg} / \mathrm{L})$ were used in experimental adsorption studies. The concentrations of both selected heavy metals were chosen as follows: $1 \cdot \mathrm{MAC}$, $2 \cdot \mathrm{MAC}, 5 \cdot \mathrm{MAC}, 10 \cdot \mathrm{MAC}, 20 \cdot \mathrm{MAC}$. The maximum allowable concentration (MAC) of lead and zinc ions in wastewater which is allowed to discharge to wastewater collection system is 0.5 and $3.0 \mathrm{mg} / \mathrm{L}$, respectively [14]. These heavy metal solutions were prepared by diluting the standard metal solution $\left(1000 \pm 2 \mathrm{mg} / \mathrm{L}, 2 \% \mathrm{HNO}_{3}\right)$ to the $0.1 \mathrm{~L}$ with deionised water.

Effect of adsorption time on removal of heavy metals. The adsorption time is assessed by analysing the static heavy metals adsorption from the aqueous solution. The aim of these experiments was to determine the time when the equilibrium of adsorption is achieved. The following durations $(5,15,30,60,240$ and $480 \mathrm{~min}$ ) were selected for adsorption research. The experiments of static heavy metals adsorption from aqueous solution were performed by mixing an adsorbent with the heavy metal solution on a 1:100 ratio ( $1 \mathrm{~g}$ of adsorbent and $0.1 \mathrm{~L}$ of aqueous solution) using capped bottles $(0.2 \mathrm{~L})$. The suspensions were shaken at $20 \mathrm{rpm}$ for mentioned contact time, at $21{ }^{\circ} \mathrm{C}$ applying Rotoshake RS12. The samples were filtered (using glass filter with $0.45 \mu \mathrm{m}$ pores) and heavy metal concentrations were measured in solutions by AAS method [15].

Effect of pH on removal of heavy metals. The analysis of adsorption efficiency of lead(II) and zinc(II) ions in different media had been performed. Adsorption efficiency was tested at $\mathrm{pH} 2,3,4,5$ and $6 . \mathrm{pH}$ was adjusted with $0.01 \mathrm{~N}\left(\mathrm{HNO}_{3}\right)$ and $0.01 \mathrm{~N}(\mathrm{NaOH})$ solutions. $\mathrm{pH}$ was measured with mettler toledo seven Multi $\mathrm{pH}$ meter. In order to avoid the formation of any hydroxide precipitation of $\mathrm{Pb}$ (II) to obstruct the adsorption process, the initial solution $\mathrm{pH}$ should be in the range of 2.0-6.0 [6].

Measurement of heavy metals concentration. The concentration of $\mathrm{Zn}$ (II) and $\mathrm{Pb}$ (II) ions was assessed by analysing the static heavy metals adsorption from the aqueous solution. The concentrations of lead(II) and zinc(II) ions were determined by using atomic absorption spectrometry (AAS; model Buck Scientific 210 VGP, USA) operated with graphite furnace, a slit of $0.7 \mathrm{~mm}$ at 283.2 and $213.9 \mathrm{~nm}$ wavelength, respectively. GFAAS samples are placed in a small graphite tube, which can then be heated to evaporate and decompose the analyte [16, 17]. A chemical modifier $\left(\mathrm{NH}_{4} \mathrm{H}_{2} \mathrm{PO}_{4}\right)$ was used for possible alleviation of matrix interferences, which are normally severe during graphite furnace analysis for heavy metals.

Evaluation of adsorption efficiency and adsorption capacity. The adsorption efficiency was calculated evaluating initial concentration of metal and its concentration after adsorption. The adsorption capacity, $Q$, of adsorbent was calculated by using the following equation $[18,19]$ :

$$
Q=\frac{\left(C_{i}-C_{f}\right) \cdot V}{m} \quad\left[\frac{\mathrm{mg}}{\mathrm{g}}\right]
$$

where $C_{i}$ - the concentration of metal ion before adsorption $[\mathrm{mg} / \mathrm{L}] ; C_{f}$ - the concentration of metal ion after adsorption at the equilibrium state $[\mathrm{mg} / \mathrm{L}] ; V-$ the volume of solution [L]; $m$ - the adsorbent mass [g].

Quality control. All chemicals and reagents were of analytical grade or higher purity and were used in the experiments as received without further purification. The solutions 
were prepared by mixing standards in deionised water from the water purification system Demiwa 3 roi (Watek, Czech Republic). Deionised water used in experiments meets the requirements of ISO standard [20]. All volumetric flasks used in the experiments were soaked for $24 \mathrm{~h}$ in $5 \mathrm{M} \mathrm{HNO}_{3}$ and then rinsed 3-4 times carefully with deionised water. All the volumetric flasks were only the highest accuracy class. High accuracy analytical balance AS 60/220.R2 (Radwag, Poland) was used for weighting. The blank solution was used for calibration. Calibration curves for heavy metal analysis using AAS were created from 5 different concentration solutions of metals. All experiments were conducted in triplicate and the mean of the three was calculated.

Statistical analysis. Statistical analysis of data was carried out. Mean, standard deviation, confidence intervals were calculated. A single factor (one-way) ANOVA was used to test the null hypothesis that the means of adsorption efficiency are equal using as criteria $p$ value. Excel 2016 software was used for Statistical parameters were estimated at $p<0.05$.

Analysis methods. The following standards were used in experiments:

- Determination of lead and zinc concentration in water was carried out according to ISO 15586:2003. Water quality - Determination of trace elements using atomic absorption spectrometry with graphite furnace [21].

- Water pH was determined according to ISO 10523:2008. Water quality Determination of $\mathrm{pH}$ [22].

According to "Council Directive 98/83/EC of 3 November 1998 on the quality of water intended for human consumption" [23] the result is acceptable, when trueness and precision of method is less than $10 \%$. Trueness is a measure of systematic error, i.e. the difference between the mean value of the large number (10 measurements) of repeated measurements and the true value. Precision is a measure of random error and is usually expressed as the standard deviation (within and between batches) of the spread of results from the mean. Acceptable precision is twice the relative standard deviation. Trueness and precision of method was tested and results for $\mathrm{Zn}(6 \mathrm{mg} / \mathrm{L})$ and $\mathrm{Pb}(5 \mathrm{mg} / \mathrm{L})$ are presented.

Trueness and precision of method

\begin{tabular}{|c|c|c|}
\hline Parameter & Trueness & Precision \\
\hline $\mathrm{Pb}$ & & 5.1 \\
\hline Average value [mg/L] & 4.9 & 5.0 \\
\hline Assigned value [mg/L] & 5.0 & 0.14 \\
\hline Standard deviation [mg/L] & 0.15 & 2.8 \\
\hline Relative standard deviation [\%] & 3.0 & 5.6 \\
\hline Acceptable trueness [\%] & 6.0 & \\
\hline Zn & & 5.85 \\
\hline Average value [mg/L] & 6.1 & 6.0 \\
\hline Assigned value [mg/L] & 6.0 & 0.14 \\
\hline Standard deviation [mg/L] & 0.16 & 2.3 \\
\hline Relative standard deviation [\%] & 2.7 & 4.6 \\
\hline Acceptable trueness [\%] & 5.4 & \\
\hline
\end{tabular}


The obtained result of the analysis is the arithmetical average of concentrations of three samples, when distribution does not exceed $6 \%$, if higher tested were repeated. $95 \%$ confidence interval was calculated.

\section{Results and discussion}

Hemp fibber consists of cellulose (55-72\%), hemicellulose (7-19\%), lignin (2-5\%), pectin (up to $1 \%$ ), fats and waxes $(0.7-1.3 \%$ ), dust (up to $4 \%$ ) [24]. The cellulose, hemicellulose and lignin content in plant fibres vary depending on the plant species, origin, quality and conditioning [25]. Adsorption occurs on the surface and pores of the adsorbent, therefore it is important to evaluate the surface of hemp fibber. Images of the fibber hemp with microscope is presented in Figure 1.

a)

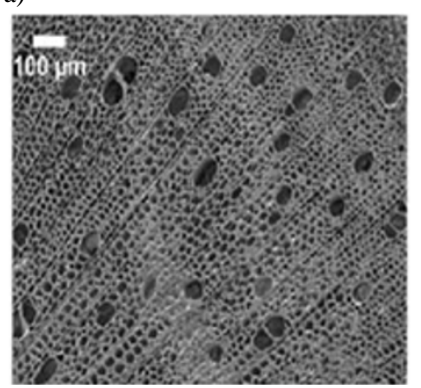

b)

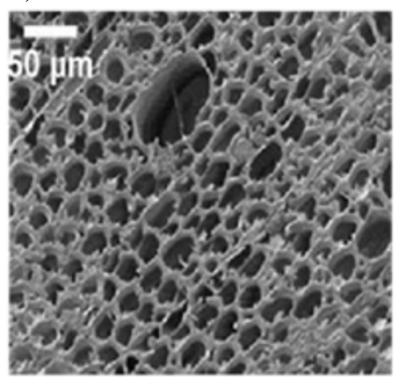

c)

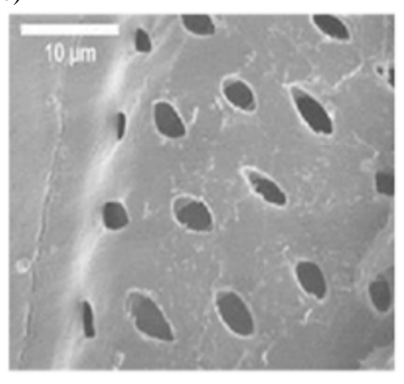

Fig. 1. Images of the fibber hemp with microscope: a) hemp fibber particle (magnification $\times 100$ ); b) hemp fibber particle (magnification $\times 300$ ); c) a wall separating the pores using MOTIC K-400 L digital microscope with a video camera Pixera VSC

The hemp fibber particle cut (Fig. 1a and b) shows that the porous structure of hemp fibber is determined by two types of voids, large and smaller. The part of larger voids are smaller than the smaller voids and occupy a smaller volume of particle. The shape of the large cells was found to be close to an ellipse with a shorter diagonal of $\sim 50 \mu \mathrm{m}$ and an elongated $\sim 70 \mu \mathrm{m}$. Smaller voids exhibit irregular shape comparing to large voids: rectangular, square, and irregularly shaped eyes with an average diameter of $\sim 15 \mu \mathrm{m}$. The voids are separated by a thin film that forms pores. The walls of the large pores are porous (Fig. 1c).

The effective parameter on heavy metals ions adsorption is size of adsorbent. Pollutant uptake during adsorption process is a function of surface of adsorbent. The fraction of fibber hemp with diameter $<200 \mu \mathrm{m}$ was selected for researches. The adsorption takes place at the surface of the adsorbent and the functional groups are responsible for the adsorption of heavy metal ions on the selected biosorbent. Functional groups of the adsorbent, such as hydroxyl, carboxyl, carbonyl, phenol, etc., play an important role in adsorption processes [26]. Cellulose has many hydroxyl groups which can be involved in various chemical reactions as it can form an insoluble, stationary phase. The chemical composition of fibber hemp depends on the type of plant and its growth conditions [27].

The biosorption of heavy metal ions $\left(\mathrm{Pb}^{2+}, \mathrm{Cd}^{2+}\right.$ and $\left.\mathrm{Zn}^{2+}\right)$ from aqueous solution by lignocellulosic material (chemically modified hemp fibbers) was investigated by scientists. Obtained results show that the biosorption process is very fast at the beginning and mainly 
determined by diffusion of the ions through the porous fibber structure. However, over a period of time the biosorption slows down due to the increase of the resistance to the further transport of metal ions through the fibbers (i.e. the electrostatic repulsive interactions between ions into the fibbers increase with the increase of the ion concentration in the fibbers) [28].

a)

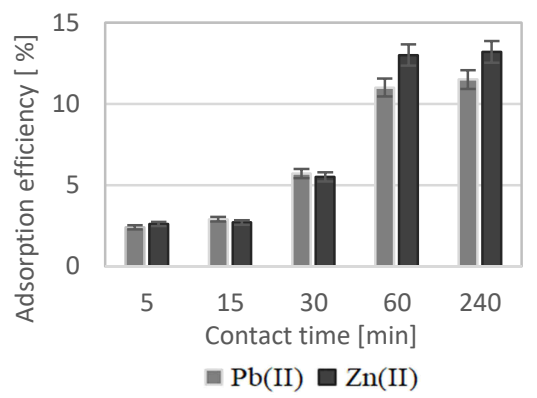

c)

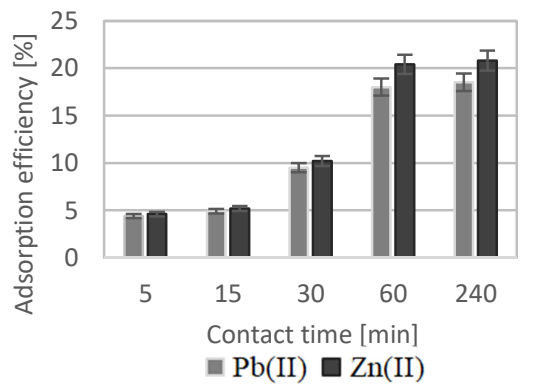

e)

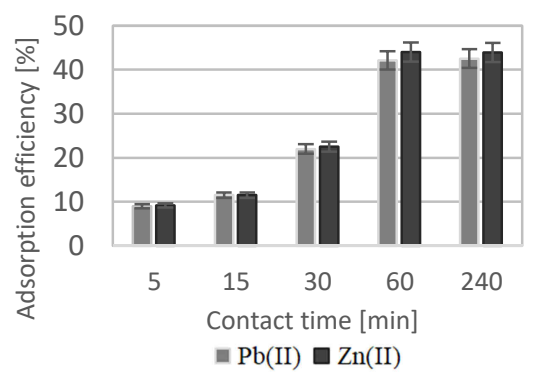

b)

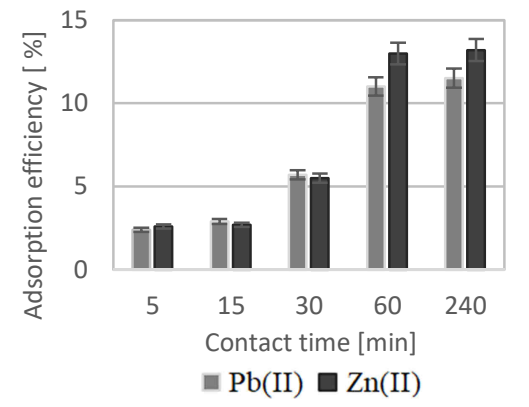

d)

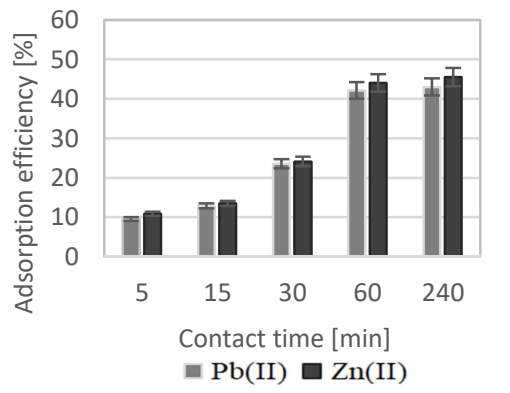

Fig. 2. Dependence of heavy metal removal efficiency on contact time, when concentration of lead(II) is $0.5 \mathrm{mg} / \mathrm{L}$, zinc(II) concentration is $3.0 \mathrm{mg} / \mathrm{L}$ : a) $\mathrm{pH}=2.0$; b) $\mathrm{pH}=3.0$; c) $\mathrm{pH}=4.0$, d) $\mathrm{pH}=5.0$; e) $\mathrm{pH}=6.0$

Effect of contact time. In order to define the kinetics of the zinc(II) and lead(II) ions adsorption, the parameters for the adsorption process were studied for contact time ranging between 5 and $240 \mathrm{~min}$, by monitoring the percent removal of zinc and lead ions by 
bioadsorbent. The efficiency of metals adsorption was calculated. The adsorption conditions were given in the figure legends. Figure 2 depicts the effect of contact time on the adsorption of $\mathrm{Zn}(\mathrm{II})$ and $\mathrm{Pb}$ (II) ions onto fibber hemp, when $\mathrm{pH}$ is constant, adsorbent solution ratio $1: 100(\mathrm{w}: \mathrm{v})$, temperature $21^{\circ} \mathrm{C}$.

a)

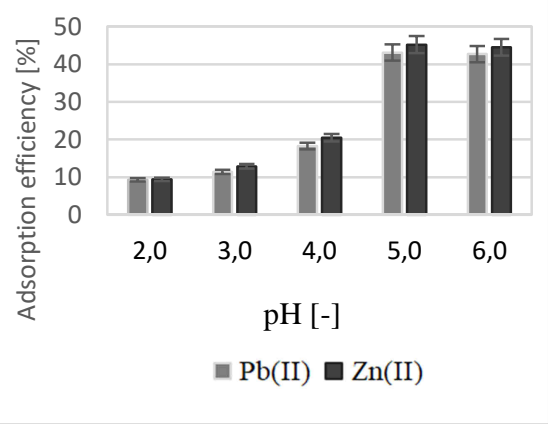

c)

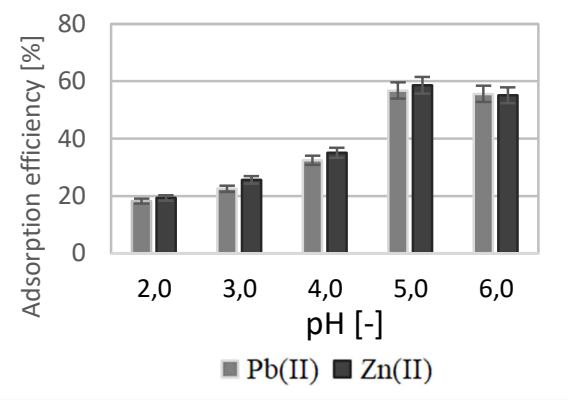

e)

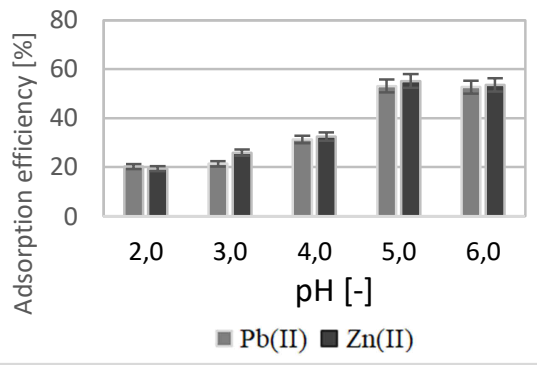

b)

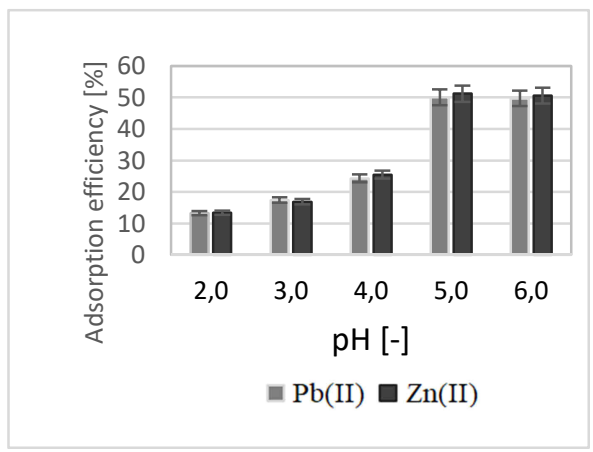

d)

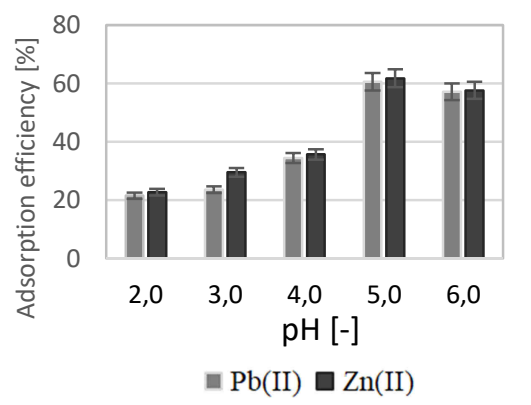

Fig. 3. Dependence of heavy metal removal efficiency on solution $\mathrm{pH}$ when: a) concentration of lead(II) is $0.5 \mathrm{mg} / \mathrm{L}$ and zinc(II) concentration is $3.0 \mathrm{mg} / \mathrm{L}$; b) concentration of lead(II) is $1.0 \mathrm{mg} / \mathrm{L}$ and zinc(II) concentration is $6.0 \mathrm{mg} / \mathrm{L}$; c) concentration of lead(II) is $2.5 \mathrm{mg} / \mathrm{L}$ and zinc(II) concentration is $15.0 \mathrm{mg} / \mathrm{L}$; d) concentration of lead(II) is $5.0 \mathrm{mg} / \mathrm{L}$ and zinc(II) concentration is $30.0 \mathrm{mg} / \mathrm{L}$; e) concentration of lead(II) is $10.0 \mathrm{mg} / \mathrm{L}$ and zinc(II) concentration is $60.0 \mathrm{mg} / \mathrm{L}$ 
The plots could be split to three distinct regions:

- $\quad$-30 min, which indicates the instantaneous adsorption of heavy metal ions, suggesting rapid external diffusion and surface adsorption;

- 30-60 min, shows a gradual equilibrium;

- 60-240 min, indicates the equilibrium state.

The adsorption equilibrium time depends on heavy metal concentration and adsorbent dose. It can be seen that the adsorbed amount of $\mathrm{Pb}$ (II) and $\mathrm{Zn}$ (II) ions increases with contact time up to $60 \mathrm{~min}$, after that a maximum removal is attained. $240 \mathrm{~min}$ was selected as the optimum contact time for further experiments.

After comparison of the obtained results with those of other scientists [9] who studied flax as an adsorbent for the removal of zinc(II) ions from aqueous solutions, it can been shown that cellulose-containing adsorbents adsorbs best, when the contact time is at least 60 min.

Figure 3 depicts the effect of solution $\mathrm{pH}$ on the adsorption of $\mathrm{Zn}$ (II) and $\mathrm{Pb}$ (II) onto fibber hemp, when contact time is $480 \mathrm{~min}$, adsorbent : solution ratio $1: 100(\mathrm{w}: \mathrm{v})$, temperature $21^{\circ} \mathrm{C}$.

\section{Effect of pH and heavy metal concentration}

Adsorption studies of $\mathrm{Pb}(\mathrm{II})$ and $\mathrm{Zn}$ (II) ions removal from aqueous solutions showed that at strong acidic solution $(\mathrm{pH}=2)$, the adsorption efficiency reached from 9.3 to $20.3 \%$ and from 9.4 to $19.4 \%$ accordingly, when $\mathrm{Pb}$ (II) concentration was $0.5-10.0 \mathrm{mg} / \mathrm{L}$ and $\mathrm{Zn}(\mathrm{II})$ ion concentration was $3.0-60.0 \mathrm{mg} / \mathrm{L}$. When $\mathrm{pH}$ was 3.0 the adsorption efficiency reached from 11.4 to $23.6 \%$ and from 12.9 to $29.5 \%$ accordingly, when $\mathrm{Pb}(\mathrm{II})$ concentration was $0.5-10 \mathrm{mg} / \mathrm{L}$ and $\mathrm{Zn}$ (II) ion concentration was 3.0-60 mg/L. When $\mathrm{pH}$ was 4, the adsorption efficiency reached from 18.3 to $34.4 \%$ and from 20.5 to $35.7 \%$ accordingly, when $\mathrm{Pb}(\mathrm{II})$ concentration was $0.5-10 \mathrm{mg} / \mathrm{L}$ and $\mathrm{Zn}(\mathrm{II})$ ion concentration was 3.0-60 mg/L. Maximum adsorption efficiency was achieved at $\mathrm{pH} 5.0$, and reached from 43.1 to $60.5 \%$ and from 45.2 to $61.7 \%$ accordingly, when $\mathrm{Pb}$ (II) concentration was $0.5-10 \mathrm{mg} / \mathrm{L}$ and $\mathrm{Zn}(\mathrm{II})$ ion concentration was 3.0-60 $\mathrm{mg} / \mathrm{L}$. When $\mathrm{pH}$ was 6 the adsorption efficiency reached from 42.7 to $57.1 \%$ and from 44.5 to $57.6 \%$ accordingly, when $\mathrm{Pb}(\mathrm{II})$ concentration was $0.5-10 \mathrm{mg} / \mathrm{L}$ and $\mathrm{Zn}(\mathrm{II})$ ion concentration was $3.0-60 \mathrm{mg} / \mathrm{L}$.

The highest fibber hemp adsorption capacity for $\mathrm{Pb}(\mathrm{II})$ was $0.53 \mathrm{mg} / \mathrm{g}$ and for $\mathrm{Zn}$ (II) $3.31 \mathrm{mg} / \mathrm{g}$ at $\mathrm{pH} 5.0$ and contact time of 240-480 min. Maximum sorption for lead ion was found also at $\mathrm{pH} 5$, studying adsorption on bamboo activated carbon [29].

Researchers carried out a study on the use of flax as an adsorbent in acidic solutions for removal of heavy metals from aqueous solutions $(\mathrm{Cd}, \mathrm{Zn}, \mathrm{Pb})$. In an experimental study at $\mathrm{pH} 5.0$ and lead(II) concentration of $10 \mathrm{mg} / \mathrm{L}$, the flax adsorption capacity was $0.189 \mathrm{mg} / \mathrm{g}$. The adsorption capacity in this experiment for lead(II) ions was similar and reached $0.194 \mathrm{mg} / \mathrm{g}$ when contact time was $480 \mathrm{~min}$. Maximum adsorption capacity of adsorbent depends on initial concentration of metal and adsorbent dosage.

The adsorption of metal ions was very small for $\mathrm{pH} 2.0$ according to research data. The results showed that $\mathrm{pH}$ is an important parameter affecting the adsorption of heavy metals. The amount of zinc and lead ions adsorbed by fibber hemp increases with the increasing in $\mathrm{pH}$ from 2.0 to 5.0.

Adsorption mechanism of fibber hemp could be explained. In the case of cations (as zinc or lead). The fibber hemp primarily contain weak acidic and basic functional 
groups. It follows from the theory of acid-base equilibria that at $2.0<\mathrm{pH}<7.0$ the binding of heavy metals cations is determined primarily by the state of dissociation of the weak acidic groups. Carboxyl groups $(-\mathrm{COOH})$ are the important (but not the unique) groups for metal uptake by these materials. When $\mathrm{pH}$ is below 3.5 most of carboxylate groups are less reactive groups for the binding of metal ions, while above $\mathrm{pH} 3.5$ the carboxylate groups are more favourable for metal ions binding [6]. The minimal adsorption at low $\mathrm{pH}$ may be due to the higher concentration and high mobility of $\mathrm{H}^{+}$, which are preferentially adsorbed rather than metal ions. Increasing the $\mathrm{pH}$ of the solution, the lower number of $\mathrm{H}^{+}$(with higher negative surface charge) results in more heavy metal adsorption. Nevertheless, at higher $\mathrm{pH}$ values determination of metal sorbed is overvalued because of metal precipitation [27]. This $\mathrm{pH}$ value depends on heavy metal concentration in solution. It can be seen that the adsorption percentages are very low at strong acidic medium for the fibber hemp.

The optimum $\mathrm{pH}$ was 5.0 for adsorption of $\mathrm{Zn}$ (II) and $\mathrm{Pb}$ (II) ions. The $\mathrm{pH}$ of the aqueous medium not only affects the solubility of the metal ions but also the ionic form in which it will be present in the solution and the type and ionic state of the functional groups at the biosorbent surface. The choice of $\mathrm{pH}$ range (2.0-6.0) evaluated in the present study was based on the fact that since approximately $5.5 \mathrm{pH}$ precipitation of $\mathrm{Pb}$ ions starts in aqueous solution $[19,28]$. Therefore, it is assumed that adsorption involves a direct contact of metal ions onto the surface of fibber hemp and thus proceeds up to monolayer coverage. In all cases, the adsorption capacity of $\mathrm{Zn}$ (II) ions onto fibber hemp was higher comparing to $\mathrm{Pb}$ (II) despite the fact that its concentration was 6 times higher in solution. Aqueous phase $\mathrm{pH}$ governs the speciation of metals and also the dissociation of active functional sites on the sorbent. It has been identified as the most important variable affecting metal adsorption onto adsorbent, this partly because hydrogen ions themselves are strongly competing with adsorbate. The adsorption efficiency depends on the $\mathrm{pH}$ of the solution containing lead(II) and zinc(II) ions. The $\mathrm{pH}$ can effect on the ionization state of the adsorbent functional groups.

Studies have shown (Figs. 2 and 3) that adsorption process efficiency of zinc and lead ions onto fibber hemp depends not only on contact time and concentration, but also on the $\mathrm{pH}$ of the solution. The remarkable results obtained in this study prompt to use the fibber hemp waste as an adsorbent for the treatment of wastewater polluted with heavy metals.

The efficiency of the adsorption process depends on the properties of metal ions, such as different molecular weights, shapes, size or polarities [30].

The adsorption capacity of the bioadsorbent increased significantly with the growth of initial concentration even though there is decrease in the adsorption efficiency. The increase of adsorption capacity can be due to growth of concentration gradient, which causes an increase in the number of metal ions coming in contact with the adsorbent. On the other hand, the number of existing adsorption sites in the adsorbent is the same for all initial concentrations. Therefore, as the initial concentration increases, more ions has to compete for the same adsorption site. This may cause many metal ions to be left without being adsorbed, thus decreasing the efficiency of the removal upon increasing the concentration of metal ions [31].

Comparison of the adsorption study results with the allowable concentrations of the selected heavy metals according to the Wastewater Testing Regulation showed that hemp fibber achieves allowable concentrations at $\mathrm{Zn}$ (II) concentration of $3.0 \mathrm{mg} / \mathrm{L}$ and $\mathrm{Pb}$ (II) concentration of $0.5 \mathrm{mg} / \mathrm{L}$. A single factor (one-way) ANOVA was used to test the null 
hypothesis that the means of adsorption efficiency for selected heavy metal $(\mathrm{Zn}$ and $\mathrm{Pb})$ are equal using as criteria $p$ value. Results of calculation are presented in Table 2.

Table 2

$p$ value

\begin{tabular}{|c|c|c|}
\hline Parameter & Pb & Zn \\
\hline Contact time, $\mathrm{pH}$ from 2 till 6 & & $7.53 \cdot 10^{-6}$ \\
\hline $5 \mathrm{~min}$ & $3.13 \cdot 10^{-5}$ & $1.26 \cdot 10^{-5}$ \\
\hline $15 \mathrm{~min}$ & $3.87 \cdot 10^{-6}$ & $6.2 \cdot 10^{-7}$ \\
\hline $30 \mathrm{~min}$ & $3.25 \cdot 10^{-6}$ & $1.02 \cdot 10^{-5}$ \\
\hline $60 \mathrm{~min}$ & $2.43 \cdot 10^{-7}$ & $1.2 \cdot 10^{-6}$ \\
\hline $240 \mathrm{~min}$ & $2.62 \cdot 10^{-7}$ & \\
\hline $\mathrm{pH}$, concentration of metal from 1 MAC till 20 MAC & & $4.65 \cdot 10^{-5}$ \\
\hline $\mathrm{pH}=2$ & $1.29 \cdot 10^{-5}$ & $4.8 \cdot 10^{-6}$ \\
\hline $\mathrm{pH}=3$ & $2.07 \cdot 10^{-5}$ & $6.59 \cdot 10^{-6}$ \\
\hline $\mathrm{pH}=4$ & 0.000147 & 0.000191 \\
\hline $\mathrm{pH}=5$ & 0.000163 & 0.001224 \\
\hline $\mathrm{pH}=6$ & 0.005218 & \\
\hline
\end{tabular}

Because the all $p$-values presented in Table 2 are lower than the significance level of 0.05 , the null hypothesis was rejected and concluded that all presented in Figures 2 and 3 values of adsorption efficiency have different means.

This adsorbent can be used in industries with low concentrations of heavy metals in wastewater, such as textiles industry. Used in adsorption fibber hemp can be regenerated and used again; burned and according to heavy metal content in ash - heavy metals could be recovered, used as fertiliser (if it meets national requirements) or ash could be utilised as dangerous waste in accordance with the laws of the Republic of Lithuania on waste management.

\section{Conclusion}

1. Metal uptake increases with an increasing of contact time. When contact time increased from 5 to $480 \mathrm{~min}$, adsorption efficiency of $\mathrm{Zn}$ (II) and $\mathrm{Pb}$ (II) increases from 10.9 to $45.2 \%$ and from 9.5 to $43.1 \%$, when solution $\mathrm{pH}$ was 5.0, concentration of $\mathrm{Zn}$ (II) ions was 3.0 and concentration of $\mathrm{Pb}$ (II) ions was $0.5 \mathrm{mg} / \mathrm{L}$. The adsorption equilibrium of investigated heavy metals was achieved after 60-240 min.

2. Experimental studies have shown that $\mathrm{pH}$ of the solution has impact on adsorption process efficiency. Zinc(II) and lead(II) ions adsorption from aqueous solutions process is most effective when the solution is weakly acidic, i.e., $\mathrm{pH}=5.0$. The highest fibber hemp adsorption capacity for $\mathrm{Pb}$ (II) was $0.53 \mathrm{mg} / \mathrm{g}$ and for $\mathrm{Zn}$ (II) $3.31 \mathrm{mg} / \mathrm{g}$ at $\mathrm{pH} 5$ and contact time of 240-480 min.

3. Comparison of the adsorption study results with the allowable concentrations of the selected heavy metals according to the Wastewater Testing Regulation showed that hemp fibber achieves allowable concentrations at $\mathrm{Zn}$ (II) concentration of $6.0 \mathrm{mg} / \mathrm{L}$ and $\mathrm{Pb}$ (II) concentration of $1.0 \mathrm{mg} / \mathrm{L}$ at $\mathrm{pH}$ of 5.0 .

4. This study showed that fibber hemp can be used for lead(II) and zinc(II) ions removal from polluted water as eco-friendly potential biosorbent.

5. The regeneration of the selected biosorbent could be an object for further experimental studies. 


\section{References}

[1] Barakat MA. Arab J Chem. 2011;4:361-77. DOI: 10.1016/j.arabjc.2010.07.019.

[2] Islam S, Islam S, Islam SA, Eaton DW. Environ Nanotechnol Monit Manage. 2016;5:74-80. DOI: 10.1016/j.enmm.2016.04.001.

[3] Shanmugapriya A, Hemalatha M, Scholastica B, Augustine TB. Der Pharma Chem. 2013;3:141-55. Available from: https://www.derpharmachemica.com/abstract/adsorption-studies-of-lead-ii-and-nickel-iiions-on-chitosangpolyacrylonitrile-11696.html.

[4] Park HJ, Jeong SW, Yang JK, Kim BG, Lee SM. J Environ Sci. 2007;12:1436-41. DOI: 10.1016/s1001-0742(07)60234-4.

[5] Igwe JC, Abia AA. Ecletica Quim. 2007;1:33-42.DOI: 10.1590/s0100-46702007000100005.

[6] Zhan W, Xu C, Qian G, Huang G, Tang X, Lin B. RSC Adv. 2018;33:18723-33. DOI: 10.1039/c8ra02055h.

[7] Bilal M, Shah JA, Ashfaq T, Gardazi SMH, Tahir AA, Pervez A, et al. J Hazard Mater. 2013;263:322-33, DOI: 10.1016/j.jhazmat.2013.07.071.

[8] Zhao M, Xu Y, Zhang C, Rong H, Zeng G. Appl Microbiol Biotechnol. 2016;100:6509-18. DOI: 10.1007/s00253-016-7646-X.

[9] Agintas A, Valentukevičienė M. Science-Future Lithuania. 2009;1:7-10. DOI: 10.3846/mla.2009.1.01.

[10] Zwain HM, Vakili M, Dahlan I. Int J Chem Eng. 2014;4:1-13. DOI: 10.1155/2014/347912.

[11] Tabatabaee A, Dastgoshadeh F, Tabatabaee A. Int J Environ Ecol Eng. 2014;9:699-704. Available from: https://waset.org/publications/10003948/biosorption-of-heavy-metals-by-low-cost-adsorbents.

[12] Natural fibber. 2017. Available from: https://www.naturalfibber.eu/lt.

[13] Mahvi HA, Nagihipour D, Vaezi F, Nazmara S. Am J Appl Sci. 2005;1:372-5. DOI: 10.3844/ajassp.2005.372.375.

[14] Regulation on wastewater management, Official Gazette, No. 110-4522, 2007. Available from: https://e-seimas.lrs.lt/portal/legalAct/lt/TAD/TAIS.307075.

[15] Salam OEA, Reiad NA, ElShafei MM. J Adv Res. 2011;2:297-303. DOI: 10.1016/j.jare.2011.01.008.

[16] Borges DLG, Holcombe JA. 2017. Graphite Furnace Atomic Absorption Spectrometry. 1-20. Available from: https://onlinelibrary.wiley.com/doi/abs/10.1002/9780470027318.a5108.pub3.

[17] Graphite Furnace Atomic Absorption Spectrometer. Available from: https://www.bucksci.com/products/220gf-atomic-absorption-graphite-furnace-package.

[18] Argun ME, Dursun S. Bioresour Technol. 2008;7:2516-27. DOI: 10.1016/j.biortech.2007.04.037.

[19] Kyzas GZ. Mat. 2012;10:1826-40. DOI: 10.3390/ma5101826.

[20] CEN EN ISO 3696:1995. Water for analytical laboratory use. Specification and test methods (ISO 3696:1987). Available from: https://standards.iteh.ai/catalog/standards/cen/299cb0e1-d6fb-43d5-b8aded96735cf50d/en-iso-3696-1995.

[21] ISO 15586:2003. Water quality - Determination of trace elements using atomic absorption spectrometry with graphite furnace. Available from: https://www.iso.org/standard/38111.html.

[22] ISO 10523:2008. Water quality - Determination of pH. Available from: https://www.iso.org/standard/51994.html.

[23] Council Directive 98/83/EC of 3 November 1998 on the quality of water intended for human consumption. Available from: https://eur-lex.europa.eu/legal-content/EN/TXT/?uri=CELEX:31998L0083.

[24] Kremensas A. Development and research of building biocomposite board from fibre hemp shives. Doctoral dissertation. Vilnius. 2018;140. DOI: 10.20334/2018-050-M.

[25] Blackburn RS, editor. Biodegradable and Sustainable Fibres. Cambridge: Woodhead Publishing Series in Textiles: 47, The Textile Institute. 2005. DOI: 10.1201/9781439823781.

[26] Gupta VK, Agarwal S, Bharti AK, Sadegh H. J Mol Liq. 2017;230:667-73. DOI: 10.1016/j.molliq.2017.01.083.

[27] Minamisawa M, Minamisawa H, Yoshida S, Takai N. J Agric Food Chem. 2004;18:5606-11. DOI: 10.1021/jf0496402.

[28] Pejic BM, Vukcevic MM, Pajic-Lijakovic ID, Lausevic MD, Kostic MM. Chem Eng J. 2011;1:354-60. DOI: 10.1016/j.cej.2011.06.016.

[29] Khan MA, Alemayehu A, Duraisamy R, Berekete AK. Int J Water Res. 2015;2:33-46. Available from: https://www.researchgate.net/profile/Masood_Khan13/publication/281810670_Removal_of_Lead_ion_from _aqueous_solution_by_Bamboo_activated_Carbon/links/5725a0cb08ae262228adc206/Removal-of-Leadion-from-aqueous-solution-by-Bamboo-activated-Carbon.pdf.

[30] Dutta A, Diao Y, Jain R, Rene ER, Dutta S. J Environ Eng. 2015;5001-14. DOI: 10.1061/(ASCE)EE.1943-7870.0001015.

[31] Yadla SB, Sridevi V, Lakshmi MVVC. J Chem Biol Phys Sci. 2012;3:1585-93. Available from: http://www.jcbsc.org/test/issueenv.php? volume=2\&issue $=3$. 